\title{
Effects of Door-In to Door-Out Time on Mortality Among ST-Segment Elevation Myocardial Infarction Patients Transferred for Primary Percutaneous Coronary Intervention
}

\author{
- Systematic Review and Meta-Analysis -
}

\author{
Junichi Yamaguchi, MD, PhD; Tetsuya Matoba, MD, PhD; Migaku Kikuchi, MD, PhD; \\ Yuichiro Minami, MD, PhD; Sunao Kojima, MD, PhD; Hiroyuki Hanada, MD, PhD; \\ Toshiaki Mano, MD, PhD; Takahiro Nakashima, MD, PhD; Katsutaka Hashiba, MD, PhD; \\ Takeshi Yamamoto, MD, PhD; Akihito Tanaka, MD, PhD; Kunihiro Matsuo, MD, PhD; \\ Naoki Nakayama, MD, PhD; Osamu Nomura, MD, PhD; Yoshio Tahara, MD, PhD; \\ Hiroshi Nonogi, MD, PhD; for the Japan Resuscitation Council (JRC) \\ Acute Coronary Syndrome (ACS) Task Force and the Guideline Editorial Committee \\ on Behalf of the Japanese Circulation Society (JCS) Emergency and Critical Care Committee
}

\begin{abstract}
Background: Primary percutaneous coronary intervention (PCl) for ST-elevation myocardial infarction (STEMI) is now widely accepted. Recent guidelines have focused on total ischemic time, because shorter total ischemic time is associated with a more favorable prognosis. The door-in to door-out (DIDO) time, defined as time from arrival at a non-PCl-capable hospital to leaving for a $\mathrm{PCl}$-capable hospital, may affect STEMI patient prognosis. However, a relevant meta-analysis is lacking.

Methods and Results: We searched PubMed for clinical studies comparing short-term (30-day and in-hospital) mortality rates of STEMI patients undergoing primary PCI with DIDO times of $\leq 30 \mathrm{vs}$. $>30 \mathrm{~min}$. Two investigators independently screened the search results and extracted the data. Random effects estimators with weights calculated by the inverse variance method were used to determine pooled risk ratios. The search retrieved 1,260 studies; of these, 2 retrospective cohort studies (15,596 patients) were analyzed. In the DIDO time $\leq 30$ and $>30$ min groups, the primary endpoint (i.e., in-hospital or 30-day mortality) occurred for 51 of $1,794(2.8 \%)$ and 831 of $13,802(6.0 \%)$ patients, respectively. The incidence of the primary endpoint was significantly lower in the DIDO time $\leq 30$ min group (odds ratio 0.45 ; 95\% confidence interval $0.34-0.60$ ).
\end{abstract}

Conclusions: Our findings suggest that a DIDO time $\leq 30 \mathrm{~min}$ is associated with a lower short-term mortality rate. However, further larger systematic reviews and meta-analyses are needed to validate our findings.

Key Words: Door-in to door-out time; Primary percutaneous coronary intervention; Reperfusion; ST-elevation myocardial infarction

$\mathbf{P}$ rimary percutaneous coronary intervention (PCI) for patients with ST-elevation myocardial infarction (STEMI) is now widely accepted as an acute treatment. The efficacy of timely PCI has also been established. ${ }^{1}$ A recent analysis of 20,042 acute coronary syndrome (ACS) patients from a Japanese nationwide registry revealed that the overall 30 -day all-cause mortality rate of
STEMI $(n=10,242)$ who undergoing primary PCI was $4 \%{ }^{2}$ A previous guideline recommended a door-to-balloon time of $<90 \mathrm{~min}$ when STEMI patients are admitted to PCIcapable hospitals. ${ }^{3}$ However, the CREDO-Kyoto Acute Myocardial Infarction (AMI) Registry, a large-scale observational study of AMI in Japan, revealed that long-term clinical outcomes were not significantly different between

Received January 6, 2022; revised manuscript received January 31, 2022; accepted February 8, 2022; J-STAGE Advance Publication released online February 25, 2022

Department of Cardiology, Tokyo Women's Medical University, Tokyo (J.Y., Y.M.); Department of Cardiovascular Medicine, Kyushu University Faculty of Medical Sciences, Fukuoka (T. Matoba); Department of Cardiovascular Medicine, Emergency and Critical Care Center, Dokkyo Medical University, Tochigi (M.K.); Department of Internal Medicine, Sakurajyuji Yatsushiro Rehabilitation Hospital, Yatsushiro (S.K.); Department of Emergency and Disaster Medicine, Hirosaki University, Hirosaki (H.H., O.N.); Department of Cardiology, Kansak Rosai Hospital, Amagasaki (T. Mano), Japan; Department of Emergency Medicine and Michigan Center for Integrative Research in Critical Care, University of Michigan, Ann Arbor, MI (T.N.), USA; Department of Cardiology, Saiseikai Yokohama-shi Nanbu Hospital, Yokohama (K.H.); Division of Cardiovascular Intensive Care, Nippon Medical School Hospital, Tokyo (T.Y.); Department of Cardiology, Nagoya University Graduate School of Medicine, Nagoya (A.T.); Department of Acute Care Medicine, Fukuoka University Chikushi Hospital, Fukuoka (K.M.); 
patients who had a door-to-balloon time $<90 \mathrm{~min}$ and those who did not. ${ }^{4}$ A door-to-device time $<90 \mathrm{~min}$ is still the minimum acceptable time, but not the target time. The goal should be to make the time from the onset of STEMI to reperfusion as short as possible, considering that a shorter total ischemic time is associated with a more favorable prognosis. The ability of non-PCI-capable hospitals to rapidly identify patients with STEMI and transfer them to PCI-capable hospitals to shorten total ischemic time is critical. Several studies have already reported the importance of door-in to door-out (DIDO) time, defined as the time interval from arrival at a non-PCI-capable hospital to transfer to a PCI hospital.5-7 Previous guidelines for STEMI recommended that the DIDO time should be $\leq 30 \mathrm{~min},{ }^{\mathbf{8}}$ and this has been widely adopted as an essential metric of the quality of STEMI care. ${ }^{3}$ In addition, factors associated with DIDO times have been investigated. , $, 7,9-12^{-12}$ However, a meta-analysis of recent relevant studies is lacking. Accordingly, this systematic review aimed to clarify the association between DIDO time and short-term mortality among STEMI patients transferred for primary PCI by analyzing the recent literature.

\section{Methods}

The Japan Resuscitation Council (JRC) ACS Task Force was established for the JRC guideline 2020 organized by the Japanese Circulation Society, the Japanese Association of Acute Medicine, and the Japanese Society of Internal Medicine. The JRC ACS Task Force set 12 clinically relevant questions against which this systematic review was conducted. Based on a discussion between the JRC ACS Task Force and the Guidelines Editorial Committee, the Population Intervention Comparator Outcome Study design and Time frame (PICOST) parameters to guide a systematic review search were set as follows:

$\mathrm{P}$ (population): STEMI patients who presented to nonPCI-capable hospitals and were transferred to a PCIcapable hospital

I (interventions): DIDO time $\leq 30 \mathrm{~min}$

$\mathrm{C}$ (comparators, controls): DIDO time $>30 \mathrm{~min}$

$\mathrm{O}$ (outcomes): in-hospital or 30-day mortality

$\mathrm{S}$ (study design): observational trials (there were no randomized control trials [RCTs]) published in English, excluding review papers

T (time frame): all literature published up to April 15, 2020.

This systematic review and meta-analysis was performed according to the Preferred Reporting Items for Systematic Reviews and Meta-Analyses (PRISMA). ${ }^{13,14}$

\section{Search Strategies}

Published reports in the PubMed database were systematically searched to retrieve relevant articles for review. We searched for full-text papers describing interventions in humans published before April 2020. A combination of key terms was used to establish the search strategy

\section{(Supplementary Figure 1).}

\section{Study Selection and Inclusion Criteria}

The study population consisted of adult patients with ACS in an emergency setting that included prehospital care. We did not restrict our analysis by country; however, we included only studies published in English. We sought to determine whether DIDO time affected short-term mortality rates among STEMI patients who underwent primary PCI. Outcomes were compared between DIDO times $\leq 30$ and $>30 \mathrm{~min}$. The critical outcome for this study was short-term mortality, which included 30-day and in-hospital mortality.

\section{Risk of Bias Assessment}

The Cochrane Risk of Bias Tool (Review Manager 5.3; The Nordic Cochrane Center, Cochrane Collaboration, Copenhagen, Denmark) was used to appraise RCTs, non-RCTs, interrupted time series, and controlled beforeand-after studies. Experienced pairs of reviewers (J.Y., T. Matoba) independently appraised the risk of bias in all the included studies. Studies were categorized as having a "low", "unclear", or "high" risk of bias in each domain. The risk of bias for each element was considered "high" when bias was present and likely to affect the outcomes and "low" when bias was not present or was present but unlikely to affect the outcomes.

\section{Data Extraction and Management}

The following data were extracted: author(s), title, journal name, year of publication, website (URL), and abstract. Two independent reviewers (J.Y., T. Matoba) screened the abstracts and titles of the studies and subsequently reviewed the full texts. Disagreements were resolved by a third reviewer (H.N.).

\section{Rating Evidence Certainty}

We used the Grading of Recommendations Assessment, Development, and Evaluation (GRADE) tool to rate the certainty of the evidence as to whether the DIDO time affected short-term mortality among STEMI patients transferred for primary PCI. ${ }^{15-18}$ The confidence of the evidence was assessed as "high", "moderate", "low", or "very low" by evaluating the risk of bias, inconsistency, indirectness, imprecision, and publication bias.

\section{Statistical Analysis}

Results were summarized using a random effects model to facilitate the pooling of estimates of the treatment effects. Odds ratios (ORs) and 95\% confidence intervals (CIs) are used to express dichotomous outcomes. Heterogeneity between trials for each outcome was evaluated using the $\mathrm{I}^{2}$ statistic to quantify inconsistency, ${ }^{19}$ and the findings were considered significant if the reason for heterogeneity could not be explained and the $\mathrm{I}^{2}$ value was $\geq 50 \%$. A funnel plot was generated to investigate potential publication bias. The estimates for each outcome were pooled using a ran-

Department of Cardiology, Kanagawa Cardiovascular and Respiratory Center, Yokohama (N.N.); Department of Cardiovascular Medicine, National Cerebral and Cardiovascular Center, Suita (Y.T.); and Faculty of Health Science, Osaka Aoyama University, Minoh (H.N.), Japan

T. Matoba is a member of Circulation Reports' Editorial Team.

Mailing address: Migaku Kikuchi, MD, PhD, Department of Cardiovascular Medicine, Emergency and Critical Care Center, Dokkyo Medical University, 880 Kitakobayashi, Mibu, Shimotsugagun, Tochigi 321-0293, Japan. E-mail: kikuchim@dokkyomed.ac.jp All rights are reserved to the Japanese Circulation Society. For permissions, please e-mail: cr@j-circ.or.jp ISSN-2434-0790 


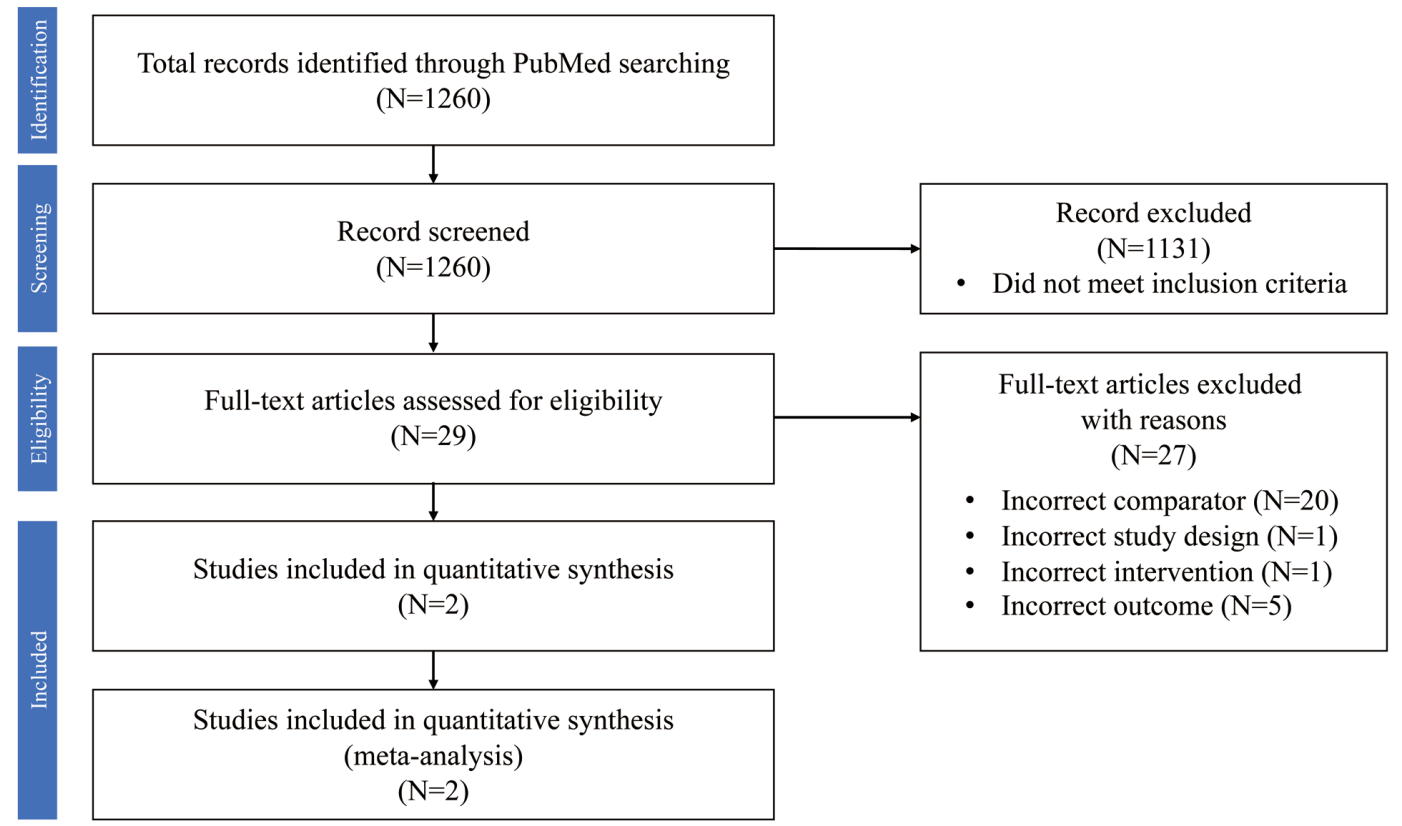

Figure 1. Preferred Reporting Items for Systematic Reviews and Meta-Analyses (PRISMA) flowchart of randomized and observational studies published between PubMed inception and April 15, 2020.

\begin{tabular}{|c|c|c|c|c|c|}
\hline Study & Year & Study type & Patients & Comparison & Outcomes \\
\hline Wang et $a^{6}$ & 2011 & $\begin{array}{l}\text { Retrospective } \\
\text { cohort study }\end{array}$ & $\begin{array}{l}14,821 \text { patients with STEMI transferred } \\
\text { to } 298 \text { STEMI receiving centers for } \\
\text { primary PCI in the ACTION Registry-Get } \\
\text { With the Guidelines }{ }^{23} \text { between January } \\
2007 \text { and March } 2010 \text { (USA) }\end{array}$ & $\begin{array}{l}\text { DIDO } \leq 30 \mathrm{~min} \\
(n=1,627) \text { vs. } \\
\text { DIDO }>30 \mathrm{~min} \\
(n=13,194)\end{array}$ & $\begin{array}{l}\text { Factors associated with } \\
\text { a DIDO time }>30 \text { min, } \\
\text { overall DTB times, and } \\
\text { risk-adjusted in-hospital } \\
\text { mortality }\end{array}$ \\
\hline Shi et $\mathrm{al}^{7}$ & 2018 & $\begin{array}{l}\text { Retrospective } \\
\text { cohort study }\end{array}$ & $\begin{array}{l}966 \text { STEMI patients transferred for } \\
\text { primary PCI in the Ontario portion of the } \\
\text { Canadian Institute for Health Information } \\
\text { Discharge Abstract Database and } \\
\text { National Ambulatory Care Reporting } \\
\text { System between January and December } \\
2012 \text { (Canada) }\end{array}$ & $\begin{array}{l}\text { DIDO } \leq 30 \text { min } \\
(n=194) \text { vs. DIDO } \\
>30 \mathrm{~min}(n=722)\end{array}$ & $\begin{array}{l}\text { Independent predictors } \\
\text { of timely DIDO as well } \\
\text { as the association } \\
\text { between DIDO times } \\
\text { and } 30 \text {-day mortality }\end{array}$ \\
\hline
\end{tabular}

DIDO, door-in door-out; DTB, door to balloon time; PCI, percutaneous coronary intervention; STEMI, ST-elevation myocardial infarction.

dom effects model, and the meta-analysis was performed based on all available published data. All analyses were performed using Review Manager software 5.3.

\section{Results}

\section{Study Selection}

We identified 1,260 studies in PubMed. Only 29 remained after the title and abstract review. The full-text review process eliminated another 27 studies because of an inappropriate comparator, study design, intervention, or outcome. This left 2 retrospective cohort studies ${ }^{6,7}$ that were included in the present meta-analysis (Figure 1).

\section{Study Characteristics}

The characteristics of the included studies are summarized in Table 1. In all, 15,596 patients were included in the 2 retrospective cohort studies. ${ }^{67}$ In both studies, patients who received fibrinolytic therapy at the non-PCI-capable hospital were excluded to enable examination of the performance related to the timeliness of primary PCI. There were 1,821 patients with a DIDO time $\leq 30 \mathrm{~min}$ and 13,916 patients with a DIDO time $>30 \mathrm{~min}$. The patients' characteristics are summarized in Table 2.6,7

\section{Outcomes}

A forest plot of the primary outcome is shown in Figure 2. The primary endpoint, in-hospital or 30-day mortality, was observed in 51 of 1,794 patients $(2.8 \%)$ in the group with a DIDO time $\leq 30 \mathrm{~min}$ and in 831 of 13,802 patients $(6.0 \%)$ with a DIDO time $>30 \mathrm{~min}$. The incidence of the primary endpoint was significantly lower in the group with a DIDO time $\leq 30 \mathrm{~min}$ than in the group with a DIDO time $>30 \mathrm{~min}$ (OR 0.45 [95\% CI 0.34-0.60]; 34 fewer per 1,000 [ $95 \%$ CI 41 fewer to 25 fewer]; Table 3). 


\begin{tabular}{|c|c|c|c|c|c|}
\hline Study & Year & $\begin{array}{l}\text { DIDO time } \\
\text { (min) }\end{array}$ & No. patients & Age & Males \\
\hline \multirow[t]{2}{*}{ Wang et $a^{6}$} & 2011 & $\leq 30$ & 1,627 & $58[50-67]^{\mathrm{A}}$ & $1,269(78.0)$ \\
\hline & & $>30$ & 13,194 & $61[52-71]^{\mathrm{A}}$ & $9,151(69.4)$ \\
\hline \multirow[t]{8}{*}{ Shi et al ${ }^{7}$} & 2018 & $\leq 30$ & 194 & 18-55 years: 87 (44.8) & $161(83.0)$ \\
\hline & & & & 56-65 years: 51 (26.3) & \\
\hline & & & & $66-75$ years: 36 (18.6) & \\
\hline & & & & $\geq 75$ years: $20(10.3)$ & \\
\hline & & $>30$ & 722 & $18-55$ years: $230(29.8)$ & $555(74.9)$ \\
\hline & & & & 56-65 years: $234(30.3)$ & \\
\hline & & & & 66-75 years: 154 (19.9) & \\
\hline & & & & $\geq 75$ years: $154(19.9)$ & \\
\hline
\end{tabular}

\begin{tabular}{|c|c|c|c|c|c|c|}
\hline Study & Hypertension & Diabetes & Previous MI & Previous stroke & $\begin{array}{l}\text { After-hours } \\
\text { presentation }\end{array}$ & $\begin{array}{l}\text { EMS transport to } \\
\text { first hospital }\end{array}$ \\
\hline \multirow[t]{2}{*}{ Wang et al ${ }^{6}$} & $910(55.9)$ & 271 (16.7) & 263 (16.2) & $50(3.1)$ & $1,001(61.5)$ & $472(29.0)$ \\
\hline & $8,277(62.7)$ & $3,246(24.6)$ & $2,333(17.7)$ & $723(5.5)$ & $8,720(66.1)$ & $3,589(27.2)$ \\
\hline \multirow[t]{2}{*}{ Shi et $\mathrm{al}^{7}$} & $93(47.9)$ & $39(20.1)$ & $21(10.8)$ & $7(3.6)$ & $122(62.9)$ & $91(47.0)$ \\
\hline & $390(50.5)$ & $167(21.6)$ & $99(12.8)$ & $30(30.9)$ & $508(65.8)$ & 262 (33.9) \\
\hline
\end{tabular}

Unless indicated otherwise, data are given as $\mathrm{n}(\%) .{ }^{\mathrm{A}}$ Median [interquartile range] age in years. ${ }^{\mathrm{B}}$ After-hours presentation was defined as presentation to a hospital between 17:00 and 08:00 hours on weekdays and anytime on weekends (Wang et al6) or between 17:00 and 09:00 hours on weekdays and anytime on weekends (Shi et al ${ }^{7}$ ). DIDO, door-in door-out; EMS, emergency medical services; MI, myocardial infarction.

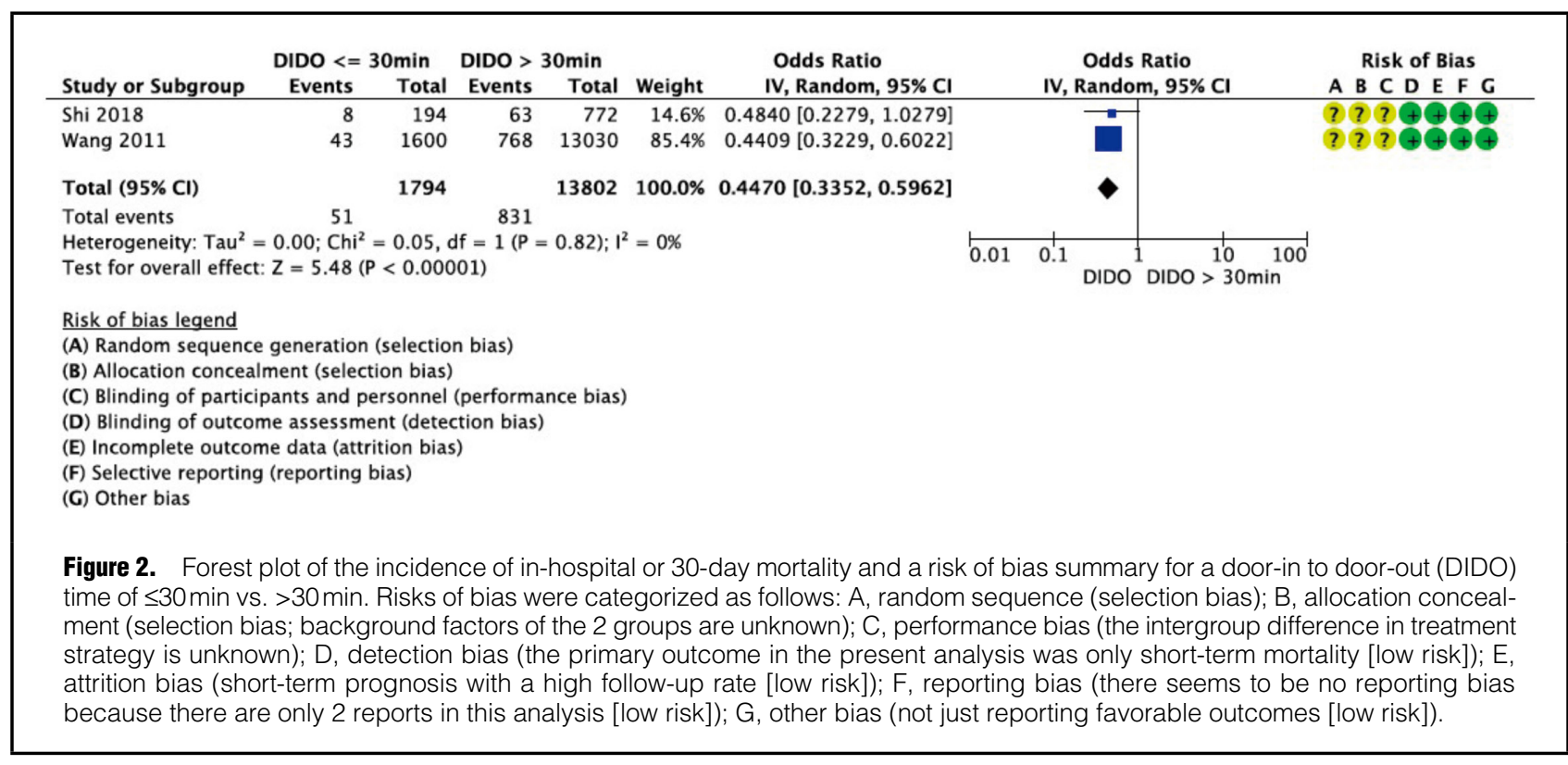

Publication Bias, Risk of Bias, and Quality of Evidence The authors' judgment about each risk of bias item for each included study is shown in Figure 2. The presence of publication bias could not be analyzed because only 2 retrospective observational studies were included in this analysis.
For reference, visual inspection of the funnel plot revealed no asymmetry for the primary endpoint (Supplementary Figure 2). The certainty of the evidence for each outcome was assessed and a summary is provided in the evidence profile in Table 3. Finally, we judged the level of evidence 


\begin{tabular}{|c|c|c|c|c|c|c|}
\hline \multirow[b]{2}{*}{ No. studies } & \multicolumn{6}{|c|}{ Certainty assessment } \\
\hline & Study design & Risk of bias & Inconsistency & Indirectness & Imprecision & $\begin{array}{c}\text { Other } \\
\text { considerations }\end{array}$ \\
\hline \multicolumn{7}{|c|}{ In-hospital or 30-day mortality } \\
\hline 2 & $\begin{array}{c}\text { Observational } \\
\text { studies }^{A}\end{array}$ & Serious & Not serious & Not serious & Serious ${ }^{B}$ & None \\
\hline
\end{tabular}

\begin{tabular}{|c|c|c|c|c|c|c|}
\hline \multirow{2}{*}{ No. studies } & \multicolumn{2}{|c|}{ No. patients } & \multicolumn{2}{|r|}{ Effect } & \multirow[b]{2}{*}{ Certainty } & \multirow[b]{2}{*}{ Importance } \\
\hline & DIDO $\leq 30 \mathrm{~min}$ & DIDO $>30 \mathrm{~min}$ & Relative $(95 \% \mathrm{CI})$ & Absolute $(95 \% \mathrm{Cl})$ & & \\
\hline \multicolumn{7}{|c|}{ In-hospital or 30 -day mortality } \\
\hline 2 & $\begin{array}{c}51 / 1,794 \\
(2.8 \%)\end{array}$ & $\begin{array}{c}831 / 13,030 \\
(6.4 \%)\end{array}$ & $\begin{array}{l}\text { OR } 0.45 \\
(0.34-0.60)\end{array}$ & $\begin{array}{l}34 \text { fewer per } 1,000 \\
\text { (from } 41 \text { fewer to } 25 \text { fewer) }\end{array}$ & Very low & Critical \\
\hline
\end{tabular}

ARetrospective cohort studies. ${ }^{\mathrm{B} T h e}$ reasons for the downgrade were the significant differences in the number of cases and background factors between the 2 retrospective cohort studies. $\mathrm{Cl}$, confidence interval; DIDO, door-in door-out; OR, odds ratio.

to be very low.

\section{Discussion}

This meta-analysis examined the effect of DIDO time on mortality among STEMI patients who underwent primary PCI. To the best of our knowledge, this study is the first to reveal that a DIDO time of $\leq 30$ min was associated with lower short-term mortality rates.

The prognosis of patients with STEMI depends on the time from onset to reperfusion of the infarct-related culprit artery. Primary PCI for STEMI within $12 \mathrm{~h}$ of symptom onset is considered appropriate and has become standard of care ${ }^{20} \mathrm{~A}$ previous guideline recommended that primary PCI should be achieved within $90 \mathrm{~min}$ of the patient's arrival at the medical institution. ${ }^{3}$ However, recent guidelines have focused on total ischemic time from the onset of STEMI, ${ }^{20,21}$ and a door-to-balloon time of $\leq 90 \mathrm{~min}$ is no longer a target.

Even in the recent era, not all STEMI patients have reached PCI-capable hospitals in a timely manner for several reasons, such as coming from suburban or outer islands. A recent study reported that the COVID-19 pandemic and the outbreak response have had adverse effects on the efficiency of primary PCI services. ${ }^{22}$ Accordingly, in the timeline for appropriate reperfusion of the infarct-related culprit artery, minimizing each component of the total ischemic time (i.e., symptom-to-door time, DIDO, doorout time to a PCI-capable hospital, and door-to-balloon time) is essential to improve the prognosis of STEMI patients.

In the present meta-analysis, we focused on DIDO time. No previous study has examined the frequency of adverse events, such as cardiac arrest, cardiac rupture, and reinfarction during transfer from non-PCI-capable hospitals to PCI-capable hospitals. Thus, the risk of maintaining a DIDO time within $30 \mathrm{~min}$ is not clear. The American College of Cardiology/American Heart Association guidelines previously recommended that the DIDO time be $<30 \mathrm{~min}$ in the timeline for transport from non-PCI-capable hospitals to PCI-capable hospitals. ${ }^{\mathbf{3}, \mathbf{8}}$

Wang et $\mathbf{l}^{6}$ reported that the median DIDO time from non-PCI-capable hospitals to PCI-capable hospitals was
$120 \mathrm{~min}$ (interquartile range [IQR] $96-159 \mathrm{~min}$ ) from the first arrival at the initial hospital, and a door-to-balloon time of $90 \mathrm{~min}$ was achieved for only $19 \%$ of all transferred patients. Furthermore, a reported $60 \%$ of patients transferred to a hospital with a DIDO time of $\leq 30 \mathrm{~min}$ achieved a door-to-balloon time of $\leq 90 \mathrm{~min}$, compared with only $13 \%$ of patients transferred to a hospital with a DIDO time of $>30 \mathrm{~min}$ (Supplementary Table).

Shi et al ${ }^{7}$ reported that the median DIDO time was $55 \mathrm{~min}$ (IQR 35-112 min), almost half of that reported by Wang et al, ${ }^{6}$ but only 194 patients $(20.1 \%)$ achieved a DIDO benchmark of $\leq 30 \mathrm{~min}$. A significantly higher proportion of those who met the DIDO benchmark also had timely first medical contact-to-balloon times, with rates almost 3 -fold higher (78.7\% vs. $27.4 \%$; $<<0.0001$; Supplementary Table). Shi et $\mathrm{al}^{7}$ also reported that after-hours presentation was one of the independent predictors of a delay in the DIDO time, suggesting it would be one of the risk factors for higher mortality in STEMI patients.

A national retrospective cohort study in the US revealed that hospital characteristics affected the DIDO time for the referral hospitals. ${ }^{5}$ Patient-level characteristics such as age, sex, heart rate, diabetes, signs of heart failure, and a history of cerebral infarction were also suggested as factors related to DIDO time. ${ }^{6}$ Other common reasons for the delay in DIDO times were awaiting transport and emergency department delays, diagnostic dilemmas, and nondiagnostic initial electrocardiography (ECG; median $81 \mathrm{~min}$; IQR $64-110.5 \mathrm{~min}),{ }^{9}$ and difficulties interpreting the ECG.10 Hospital practices to improve systems to minimize transfer time in STEMI patients are also essential. Expert consensus identified and verified 18 critical factors, including the use of emergency medical services transport, prehospital ECG, and protocols for transferring STEMI patients, among others, to minimize transfer time to PCI-capable hospitals. ${ }^{11,12}$ However, it seemed still difficult to achieve the 30-min DIDO goal and the there is a need for continued focus on strategies for reducing DIDO time, including system-wide quality improvement programs. Moreover, there are some factors for which no consensus has been reached; we propose to investigate and examine these factors in clinical practice in Japan.

Considering the geographical and medical conditions, 
the effect of DIDO time on outcomes cannot be ignored in the US and other countries. Conversely, in Japan, especially in urban areas, there are many facilities located within a short distance that can provide primary PCI for STEMI. It is necessary to note that the effect of DIDO time on outcomes may differ in Japan from that in other countries. In addition: (1) a unique system has not been constructed to verify, in Japan, whether $30 \mathrm{~min}$ is appropriate as the time to make a diagnosis, stabilize the condition, or confirm transfer to another hospital at a non-PCI-capable hospital; (2) the significance of shortening DIDO time is not sufficiently recognized by practicing clinicians; and (3) concrete methods for shortening door-to-ECG time are insufficient, meaning that many issues remain to be overcome.

\section{Study Limitations}

The results of this analysis should be interpreted in light of some significant limitations. First, this analysis consisted of only 2 retrospective cohort studies identified from a search of PubMed. One of these studies had a small sample size, ${ }^{7}$ meaning that the point estimate of this paper may be affected by another study with relatively large sample size. Information about time intervals and patient characteristics was ascertained through a retrospective chart review, and these records could not be independently validated. Moreover, the role of confounding variables in our analysis is unknown. Second, the primary endpoint was shortterm (30-day and in-hospital) mortality. We could not examine the number of patients who survived for more than 30 days or died during the index hospitalization. Third, critical factors that would affect clinical outcomes and STEMI severity (e.g., age, past medical history, Killip class, vital signs, including blood pressure on admission, and detailed PCI strategy) were not assessed in detail in the present analysis. The group with a DIDO time $>30 \mathrm{~min}$ was older, had a higher proportion of females, and had a higher frequency of hypertension and previous stroke than those the group with a DIDO time $\leq 30 \mathrm{~min}$. These differences could have influenced the present results. Finally, detailed information about the non-PCI-capable hospitals is lacking, but could have affected the diagnosis of STEMI and decisions regarding transfer.

\section{Conclusions}

This meta-analysis suggests that a DIDO time $\leq 30 \mathrm{~min}$ is associated with lower short-term mortality rates. However, further systematic reviews and meta-analyses that include more studies are needed to validate our findings.

\section{Acknowledgments}

The authors thank the Japan Council for Quality Health Care (Minds Tokyo GRADE Center) staff and Morio Aihara for their help implementing the GRADE approach. The authors also thank Editage (www.editage.com) for English language editing.

\section{Sources of Funding}

Funding was provided by the Japan Resuscitation Council and the Japanese Circulation Society Emergency and Critical Care Committee.

\section{Disclosures}

T. Matoba is a member of Circulation Reports' Editorial Team. The other authors have no conflicts of interest to declare concerning this article.

\section{IRB Information}

None.

\section{Authors Contribution}

All authors participated in the study design. J.Y. and T.M. identified the studies included in the meta-analysis and analyzed the data. J.Y., T.M., and Y.M. drafted the manuscript. Y.T., M.K., T.M., and H.N. reviewed the manuscript. All authors participated in the data interpretation and discussion. All authors had full access to all data (including statistical reports and tables) in the study and take responsibility for its integrity, the accuracy of the analysis, and review and approval of the final manuscript.

\section{References}

1. Keeley EC, Boura JA, Grines CL. Primary angioplasty versus intravenous thrombolytic therapy for acute myocardial infarction: A quantitative review of 23 randomised trials. Lancet 2003; 361: $13-20$.

2. Sawano M, Kohsaka S, Ishii H, Numasawa $Y$, Yamaji K, Inohara $\mathrm{T}$, et al. One-year outcome after percutaneous coronary intervention for acute coronary syndrome: An analysis of 20,042 patients from a Japanese nationwide registry. Circ J 2021; 85: 1756-1767.

3. Kushner FG, Hand M, Smith SC Jr, King SB 3rd, Anderson JL, Antman EM, et al. 2009 focused updates: ACC/AHA guidelines for the management of patients with ST-elevation myocardial infarction (updating the 2004 guideline and 2007 focused update) and ACC/AHA/SCAI guidelines on percutaneous coronary intervention (updating the 2005 guideline and 2007 focused update) a report of the American College of Cardiology Foundation/ American Heart Association Task Force on Practice Guidelines. J Am Coll Cardiol 2009; 54: 2205-2241.

4. Shiomi H, Nakagawa Y, Morimoto T, Furukawa Y, Nakano A, Shirai S, et al. Association of onset to balloon and door to balloon time with long term clinical outcome in patients with ST elevation acute myocardial infarction having primary percutaneous coronary intervention: Observational study. BMJ 2012; 344: e3257.

5. Herrin J, Miller LE, Turkmani DF, Nsa W, Drye EE, Bernheim $\mathrm{SM}$, et al. National performance on door-in to door-out time among patients transferred for primary percutaneous coronary intervention. Arch Intern Med 2011; 171: 1879-1886.

6. Wang TY, Nallamothu BK, Krumholz HM, Li S, Roe MT, Jollis $\mathrm{JG}$, et al. Association of door-in to door-out time with reperfusion delays and outcomes among patients transferred for primary percutaneous coronary intervention. JAMA 2011; 305: 25402547.

7. Shi O, Khan AM, Rezai MR, Jackevicius CA, Cox J, Atzema $\mathrm{CL}$, et al. Factors associated with door-in to door-out delays among ST-segment elevation myocardial infarction (STEMI) patients transferred for primary percutaneous coronary intervention: A population-based cohort study in Ontario, Canada. BMC Cardiovasc Disord 2018; 18: 204.

8. Krumholz HM, Anderson JL, Bachelder BL, Fesmire FM, Fihn SD, Foody JM, et al. ACC/AHA 2008 performance measures for adults with ST-elevation and non-ST-elevation myocardial infarction: A report of the American College of Cardiology/American Heart Association Task Force on Performance Measures (Writing Committee to Develop Performance Measures for ST-Elevation and Non-ST-Elevation Myocardial Infarction) developed in collaboration with the American Academy of Family Physicians and American College of Emergency Physicians endorsed by the American Association of Cardiovascular and Pulmonary Rehabilitation, Society for Cardiovascular Angiography and Interventions, and Society of Hospital Medicine. J Am Coll Cardiol 2008; 52: 2046-2099.

9. Miedema MD, Newell MC, Duval S, Garberich RF, Handran CB, Larson DM, et al. Causes of delay and associated mortality in patients transferred with ST-segment-elevation myocardial infarction. Circulation 2011; 124: 1636-1644.

10. Lambert LJ, Brown KA, Boothroyd LJ, Segal E, Maire S, Kouz $\mathrm{S}$, et al. Transfer of patients with ST-elevation myocardial infarction for primary percutaneous coronary intervention: A province-wide evaluation of "door-in to door-out" delays at the first hospital. Circulation 2014; 129: 2653-2660.

11. Mumma BE, Williamson C, Khare RK, Mackey KE, Diercks DB. Minimizing transfer time to an ST segment elevation myocardial infarction-receiving center: A modified Delphi consensus. 
Crit Pathw Cardiol 2014; 13: 20-24.

12. Mumma BE, Eggert J, Mahler SA, Kontos MC, Diercks DB. Association between hospital practices and door-in-door-out time in ST-segment elevation myocardial infarction. Crit Pathw Cardiol 2016; 15: 165-168.

13. Liberati A, Altman DG, Tetzlaff J, Mulrow C, Gotzsche PC, Ioannidis JP, et al. The PRISMA statement for reporting systematic reviews and meta-analyses of studies that evaluate health care interventions: Explanation and elaboration. J Clin Epidemiol 2009; 62: e1-e34.

14. Moher D, Liberati A, Tetzlaff J, Altman DG; PRISMA Group. Preferred reporting items for systematic reviews and meta-analyses: The PRISMA statement. J Clin Epidemiol 2009; 62: 1006-1012.

15. Atkins D, Eccles M, Flottorp S, Guyatt GH, Henry D, Hill S, et al. Systems for grading the quality of evidence and the strength of recommendations I: Critical appraisal of existing approaches. The GRADE Working Group. BMC Health Serv Res 2004; 4: 38

16. Atkins D, Best D, Briss PA, Eccles M, Falck-Ytter Y, Flottorp $\mathrm{S}$, et al. Grading quality of evidence and strength of recommendations. BMJ 2004; 328: 1490.

17. Mustafa RA, Santesso N, Brozek J, Akl EA, Walter SD, Norman $\mathrm{G}$, et al. The GRADE approach is reproducible in assessing the quality of evidence of quantitative evidence syntheses. $J$ Clin Epidemiol 2013; 66: 736-742.

18. Guyatt GH, Oxman AD, Schunemann HJ, Tugwell P, Knottnerus A. GRADE guidelines: A new series of articles in the Journal of Clinical Epidemiology. J Clin Epidemiol 2011; 64: 380-382.

19. Huedo-Medina TB, Sanchez-Meca J, Marin-Martinez F, Botella $\mathrm{J}$. Assessing heterogeneity in meta-analysis: Q statistic or $\mathrm{I}^{2}$ index?
Psychol Methods 2006; 11: 193-206.

20. Kimura K, Kimura T, Ishihara M, Nakagawa Y, Nakao K, Miyauchi K, et al. JCS 2018 guideline on diagnosis and treatment of acute coronary syndrome. Circ J 2019; 83: 1085-1196.

21. Levine GN, Bates ER, Blankenship JC, Bailey SR, Bittl JA, Cercek B, et al. 2015 ACC/AHA/SCAI focused update on primary percutaneous coronary intervention for patients with STelevation myocardial infarction: An update of the 2011 ACCF/ AHA/SCAI guideline for percutaneous coronary intervention and the 2013 ACCF/AHA guideline for the management of STelevation myocardial infarction: A report of the American College of Cardiology/American Heart Association Task Force on Clinical Practice Guidelines and the Society for Cardiovascular Angiography and Interventions. Circulation 2016; 133: $1135-$ 1147.

22. Chew NW, Sia CH, Wee HL, Benedict LJ, Rastogi S, Kojodjojo $\mathrm{P}$, et al. Impact of the COVID-19 pandemic on door-to-balloon time for primary percutaneous coronary intervention: Results from the Singapore Western STEMI Network. Circ J 2021; 85: $139-149$.

23. Peterson ED, Roe MT, Chen AY, Fonarow GC, Lytle BL, Cannon CP, et al. The NCDR ACTION Registry-GWTG: Transforming contemporary acute myocardial infarction clinical care. Heart 2010; 96: $1798-1802$.

\section{Supplementary Files}

Please find supplementary file(s);

http://dx.doi.org/10.1253/circrep.CR-21-0160 